$\xi=-1$

\title{
Comparative study of diabetes foot diagnosis using ABPI
}

\author{
G Hari Krishnan 1*, G S Arun Kumar ${ }^{1}$, V Arun ${ }^{1}$, R Saravana ${ }^{2}$ \\ ${ }^{1}$ Department of EEE, Sree Vidyanikethan Engineering College, Tirupati, Andhra Pradesh, India \\ ${ }^{2}$ Department of ECE, Sathyabama University, Chennai, Tamil Nadu, India \\ *Corresponding author E-mail: haris_eee@yahoo.com
}

\begin{abstract}
User friendly product has been developed to analyze the user condition accurately and provide a digital output with low cost product to the end user for diagnosing diabetes foot. Detecting the level of peripheral neuropathy which significantly increases the risk of sustaining a foot wound called 'loss of protective sensation. To implement a device to detect foot diabetes in patients using the Ankle Brachial pressure index values. The proposed system was tested by conducting experiment on 9 patients and whose ABPI value measured confirms the convention-al measured values.
\end{abstract}

Keywords: Diabetes; Food Diagnosis; ABPI; PIC Microcontroller and Blood Pressure

\section{Introduction}

To find the foot diabetes in the starting stage, researchers came with the projects Diabetic Foot Syndrome Using Plantar PressureSensitive system and Infrared Thermal Imaging for Automated Detection of Diabetic Foot [1] \& [2]. The proposed system was designed to provide more reliable equipment to the patients compared to other related equipment's on the Foot diabetes. Improvements are identified in both product usage wise and size, by our project user or the patient can use the equipment without any major assistance [3]. Earlier projects were designed in a complicated way where the output result is difficult understand by a common user without the idea of the foot diabetes, it is difficult to understand what is been the output [4]. To overcome these difficulties and these projects have motivated us to make this project to provide it as user friendly and the user can easily handle the equipment and the output can be easily understandable [5].

This also provides an advantage to the user that the cost of the equipment is very low, and the equipment will be designed as a compact that it can be stored in a small space and can be used efficiently [6] \& [7].

In color image, both the boundaries of the foot and they were manually annotated with self-designated MATLAB software [8]. This annotation was transferred to the thermal image. From the pixels encapsulated by the boundaries of the entire foot as well as those encapsulated by the boundaries of the entire foot as well as those encapsulated by the mean team standard temperature and the standard deviation across pixels were automatically processed using Matlab [9] \& [10]. [40] Pin PDIP PIC Microcontroller 16F877A used to acquire the signal form sensor and display in LCD matrix.

MPLAB Integrated Development Environment along with CCS Compiler was used to analyze the software and dumping the code in PIC Microcontroller. Proposed circuit was simulated using PROTEUS simulation software and final PCB was obtained using EXPRESSPCB. Regulated 5V power supply has been designed using bridge rectifier and regulation using IC7805. To measure the pressure variations SPD005G silicon based pressure sensor was used and output of pressure variation are available as voltage variation (mV range). 16 X 2 Matrix LCD Display was used to display the required parameter values as pressure variation [11].

The ABPI value measured at leg is in terms of ratio of systolic BP of posterior tibial arteries and the brachial systolic blood pressure [12].

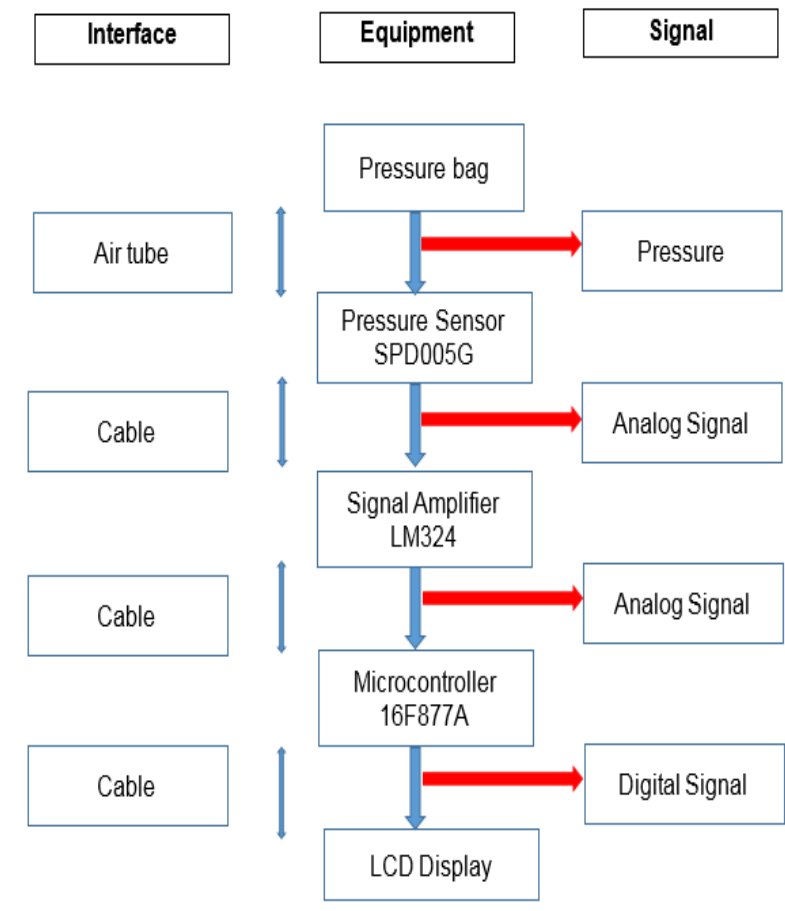

Fig. 1: Main Block Diagram.

Figure 1 shows the experimental block diagram and the experimental circuit diagram is as shown in figure 2. Technology is emerging that allows for the oscillometric calculation of $\mathrm{ABI}$, in which simultaneous readings of blood pressure at the levels of the 
ankle and upper arm are taken using specially calibrated oscillometric machines.

Provided that there are no other significant conditions affecting the arteries of the leg, the following ABPI ratios can be used to predict the severity of PAD as well as assess the nature and best management of various types of leg ulcers.

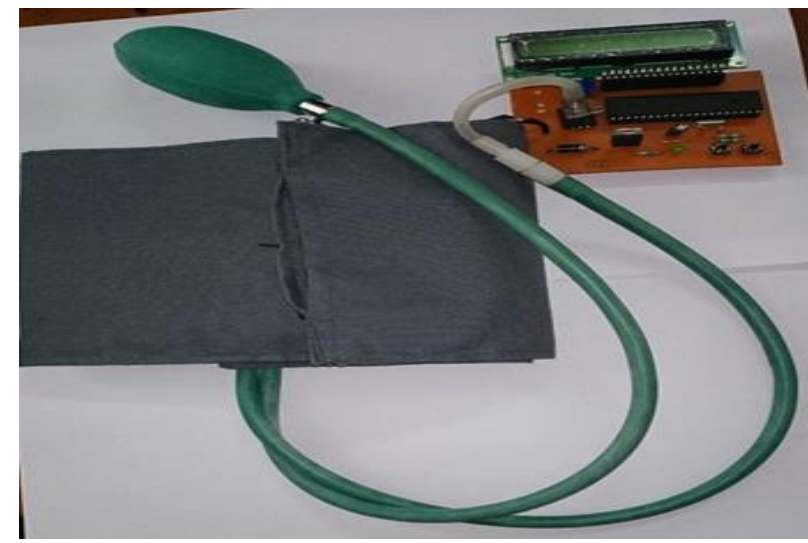

Fig. 2: Picture of ABPI Diagnosis Circuit.

Power supply provided to IC16F877 and pressure senor is taken from regulated power supply. Pressure Bag output is provided as an input to the Pressure sensor. Pressure sensor output is provided to the amplifier circuit. The Amplifier circuit provides the input to the IC 16F877. IC16F877 calculates the ABPI value received from the Arm and Ankle and provides the output to the LCD.

\section{Results and discussion}

The sensor output received was in the form of millivolt, which need to be converted into a pressure value, for this purpose we have used calibration techniques for measuring the values from the sensor and from Sphygnometer. In first case we took 5 person and connected the Sphygnometer and verified the rise of pressure (mercury) with reference to pumping count. Calibrating the sensor for pressure values with respect to pumping count for brachial values are provided below.

1) Calibrated value

Table 1: Calibrated Values

\begin{tabular}{|c|c|c|c|}
\hline Stage & Time in sec & $\begin{array}{c}\text { Volts in milli } \\
\text { volts }\end{array}$ & $\begin{array}{c}\text { Pressure in } \\
\mathrm{mmHg}\end{array}$ \\
\hline \multirow{2}{*}{$\begin{array}{l}\text { Pump } \\
\text { pressure }\end{array}$} & 1 & 14 & 12 \\
\hline & 8 & 56 & 174 \\
\hline \multirow{11}{*}{$\begin{array}{l}\text { Release the } \\
\text { pressure }\end{array}$} & 10 & 56 & 174 \\
\hline & 12 & 52 & 168 \\
\hline & 14 & 50 & 158 \\
\hline & 16 & 40 & 140 \\
\hline & 18 & 38 & 128 \\
\hline & 20 & 36 & 108 \\
\hline & 22 & 38 & 118 \\
\hline & 24 & 34 & 110 \\
\hline & 26 & 28 & 98 \\
\hline & 28 & 24 & 86 \\
\hline & 30 & 22 & 76 \\
\hline
\end{tabular}

Table 2: Different Iteration Values

\begin{tabular}{|c|c|c|c|c|c|c|}
\hline \multirow{10}{*}{ Person! } & \multirow{2}{*}{ Punping count } & leertion 1 & Ilention & Meration 3 & llertion 4 & \multirow{2}{*}{ Average } \\
\hline & & Pressurven mint & Pressuveinmmby & Pressurein mmby & Pressure in molhe & \\
\hline & 1 & 12 & 11 & 10 & 12 & 115 \\
\hline & ? & 20 & 18 & 16 & 24 & 195 \\
\hline & 3 & 34 & 24 & 12 & 42 & 30.5 \\
\hline & 4 & 54 & 42 & 40 & 10 & 515 \\
\hline & 5 & 80 & 74 & 12 & 82 & $\pi$ \\
\hline & 6 & 110 & 108 & 110 & 106 & 1085 \\
\hline & 1 & 140 & 144 & 1.0 & 140 & 141 \\
\hline & 8 & 172 & 180 & 180 & 172 & 176 \\
\hline
\end{tabular}

Below Table, represent the average values of the pressure value received from [5] persons with a single equipment, the average value has been taken corresponding to pumping count.

The calibrated values and different iteration values are as shown in figure 1 and 2 . Through this value, we can able to measure rise of pressure with each pumping count and this can be used as a reference value for rise in Millivolt while each pumping.

\begin{tabular}{|c|c|c|c|c|c|c|c|}
\hline \multirow{9}{*}{$\begin{array}{l}\text { Average } \\
\text { value }\end{array}$} & Pumping count & $\begin{array}{c}\text { Person Iin } \\
\text { mmbrg }\end{array}$ & $\begin{array}{c}\text { Person Lin } \\
\text { minhe }\end{array}$ & $\begin{array}{c}\text { Personjin } \\
\text { mmhn }\end{array}$ & $\begin{array}{l}\text { Persondin } \\
\text { minge }\end{array}$ & $\begin{array}{c}\text { Personjin } \\
\text { monhy }\end{array}$ & $\begin{array}{c}\text { Averne } \\
e\end{array}$ \\
\hline & 1 & 115 & 1225 & 11 & 1115 & 12 & 1165 \\
\hline & l & 195 & 1825 & 16 & 185 & 195 & 1835 \\
\hline & 3 & N.5. & 30.5 & 26 & 31 & $3 !$ & 298 \\
\hline & 4 & 51.5 & 51.5 & 15 & $\$ 1$ & 53.5 & So.5 \\
\hline & S & $\eta$ & 76.75 & 615 & 17.5 & 77.5 & 70.05 \\
\hline & 6 & 108.5 & 1065 & If & 108.5 & 109.5 & 10556 \\
\hline & 1 & $14 !$ & 10.75 & 1.25 & 10.5 & 139.15 & 1379 \\
\hline & 8 & 176 & 174.5 & 1645 & 1795 & 1745 & 1738 \\
\hline
\end{tabular}

2) Graphical view of the average pressure values for brachial. The below graph as shown in figure 3 represents the graphical view of 5 persons and corresponding to the rise of pressure with pumping count. 


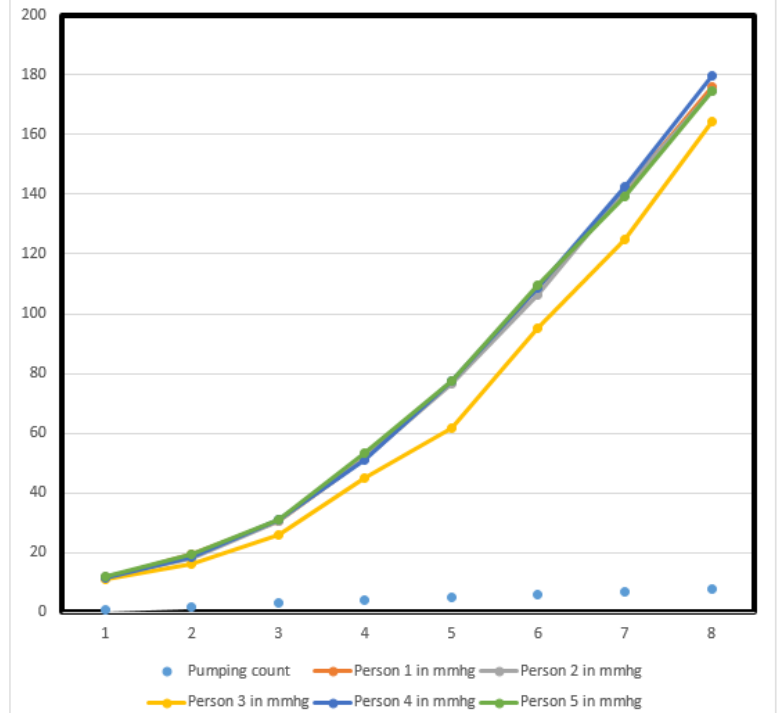

Fig. 3: Graph for Pressure Variation in Different Persons.

3) Received values from the sensor

Below table represents values received from the sensor with respective to the pumping pressure and releasing pressure. Using the reference values taken from the Sphygnometer the millivolts readings are been converted into pressure values, These value will help us to find the Blood pressure using the pressure sensor by sensing the pressure and can provide variations output as shown in figure 4.

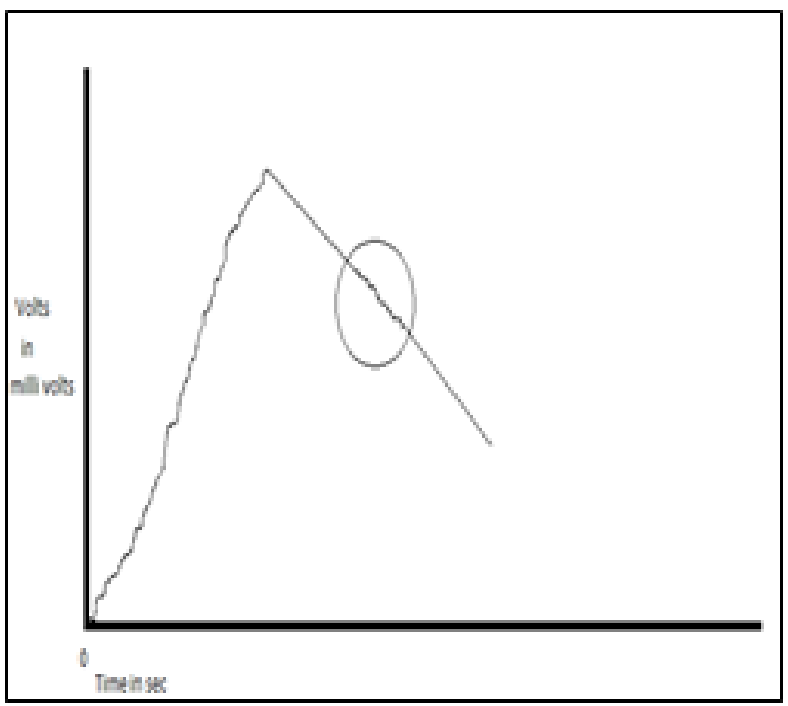

Fig. 4: Graphical View of Sensor Output.

\section{Conclusion}

The proposed system has been designed based on the standard taken form the references and hardware calibrated as per the reference reading taken from the Sphygnometer. Experimental analysis has been made by measuring ABPI values from 9 patients. Output received from the sensor confirms the ABPI value by experimenting with nine patients.

\section{References}

[1] Chongthawonsatid, Sukanya, and Somchai Dutsadeevettakul. "Validity and Reliability of the Ankle-Brachial Index by Oscillometric Blood Pressure and Automated Ankle-Brachial Index" Journal of Research in Medical Sciences: The Official Journal of Isfahan University of Medical Sciences 22 (2017).
[2] Kollias A, Xilomenos A, Protogerous A, Dimakakos E and Stegious GS, "Automated determination of the ankle-brachial index using an oscillometric blood pressure monitor: validation vs. Doppler measurement and cardiovascular risk factor profile, Hypertens Res, Volume 34(7), pp825-30 (2011).

[3] Andrea M MacDougall, MD Vikas Tandon, MD Merne P Wilson RN MSc and Thomas W Wilson, "Oscillometric measurement of the ankle-brachial index", Can J Cardiol, Vol 24(1), pp49-51 (2008).

[4] Jing Ma, Min Liu, Dawei Chen, Chun Wang, Guanjian Liu, and Xingwu Ran, "The Validity and Reliability between Automated Oscillometric Measurement of Ankle-Brachial Index and Standard Measurement by Eco-Doppler in Diabetic Patients with or without Diabetic Foot," International Journal of Endocrinology, vol. 2017.

[5] Xu, Dachun et al., "Diagnostic value of Ankle-Brachial Index in Peripheral Arterial Disease: A Meta-analysis", Canadian Journal of Cardiology, Volume 29, Issue 4, pp492-498, 2013.

[6] Van Netten,Ph.D., Jeff Van Baal,M.D.,Ph.D., Ferdi van der Heijden,Ph.D., and Sicco A.Bus,Ph.D Infrared Thermal Imaging for Automated Detection of Diabetic Foot Complications.

[7] M. Zequera, L. Garavito, W. Sandham, J. Bernal, A. Rodrguez, L.Jimnez, A. Hernndez, C. Wilches, and A. Villa, "Diabetic Foot Prevention:Repeatability of the Loran Platform Plantar Pressure and LoadDistribution Measurements in Nondiabetic Subjects during BipedalStanding: A Pilot Study," J. Electrical and Computer Engineering,vol. 2011, Article ID 136936, 2011.

[8] Herráiz-Adillo, Ángel et al. "Diagnostic Accuracy Study of an Oscillometric Ankle-Brachial Index in Peripheral Arterial Disease: The Influence of Oscillometric Errors and Calcified Legs.” Ed. Tatsuo Shimosawa. PLoS ONE11.11 (2016).

[9] Špan, Matjaž et al. "Detection of Peripheral Arterial Disease with an Improved Automated Device: Comparison of a New Oscillometric Device and the Standard Doppler Method." Vascular Health and Risk Management 12 (2016).

[10] Takahashi, Ikuno et al. "Comparison between Oscillometric- and Doppler-ABI in Elderly Individuals." Vascular Health and Risk Management 9 (2013): 89-94.

[11] Nelson, Mark R et al. "Ankle-Brachial Index Determination and Peripheral Arterial Disease Diagnosis by an Oscillometric Blood Pressure Device in Primary Care: Validation and Diagnostic Accuracy Study." BMJ Open 2.5 (2012).

[12] Rosenbaum, David et al. "Accuracy of the Ankle-Brachial Index Using the SCVL $®$, an Arm and Ankle Automated Device with Synchronized Cuffs, in a Population with Increased Cardiovascular Risk." Vascular Health and Risk Management 8 (2012): 239-246. 